\title{
Sociocultural Adaptation of U.S. Education Abroad Students in Greece: The Effects of Program Duration and Intervention
}

\author{
Efi Antonakopoulou \\ American College of Thessaloniki
}

I am not an Athenian or a Greek, but a citizen of the world - Socrates, 469-399 BC.

When students who participate in education abroad programs are first exposed to a foreign culture they undergo several psychological, behavioral, and cognitive adjustments. Upon arrival in the host country, they are confronted with a variety of problems as they adjust to the new surroundings. These could range from language barriers and homesickness, to depression and an inability to participate in social interactions. Research on sociocultural adaptation and adjustment has produced several theories, but for the purpose of this study, the sociocultural adaptation theory, as it has been proposed by Ward and Kennedy (1999), will be used. They, and others (Searle \& Ward, 1990; Searle \& Ward, 1999), attempted to address the issue of what actually constitutes a sojourner adaptation by developing the construct of sociocultural adaptation. They differentiated between the psychological adaptation, which addresses the emotional/affective domain and is associated with factors dealing with the mental health of the individuals, and the sociocultural adaptation, which addresses the behavioral domain and is associated with factors dealing with school, work, or family issues; these two adjustment outcomes, although closely related, represent conceptually and empirically distinct domains. Psychological adjustment precedes sociocultural adaptation. Ward (2001) emphasized that there is a learning-curve while sojourners adjust to their new culture and that "culture specific skills are required to negotiate the new cultural milieu" (p. 413). Skills are increased as sojourners spend more time in the host culture and, thus, cultural learning is increased. Gains in learning new skills allow for greater use of the skills applied in new situations. Cultural distance between the host and the home country and length of time spent abroad, have been suggested as important factors which determine how skillfully these sociocultural adjustments are made. In dissimilar cultures, the number and the intensity of the encounters will be higher, and the differences will be more pronounced than in similar cultures (Savicki, Adams, \& Binder, 2008). It is commonly assumed, therefore, that different degrees of sociocultural adaptation will take place based on the time period spent abroad. The longer the sojourner stays abroad, the greater the contact with the local culture and the greater the possible gains in sociocultural adaptation. 


\section{Sociocultural Adaptation and Education Abroad}

Although studies dealing with the overall intercultural development of U.S. students who participate in education abroad programs are abundant in literature, a smaller number of researchers have embarked upon empirical investigations on cross-cultural transitions and adaptations of this population. In this review, indicative studies that relate most directly to the objectives of the present research are reviewed. Searle and Ward (1990) used the Sociocultural Adaptation Scale (SCAS) to study the sociocultural transition and adaptation of Malaysian and Singaporean students in New Zealand. Their findings emphasized the importance of the difference between psychological wellbeing and social competency for someone who attempts to study the students' experiences in crosscultural transitions. Ward and Searle (1991), and others (Allen, Dritsas, \& Mills, 2006; Searle \& Ward, 1990; Ward \& Chang, 1997; Ward \& Kennedy, 1993; Ward \& Kennedy, 1994), emphasized the importance of several factors which could influence the development of crosscultural identification and understanding such as ethnocentrism, rigidity, authoritarianism, previous cultural knowledge and traveling, language fluency, and cultural distance. Using a modified version of the SCAS, Spencer-Oatey and Xiong (2006) studied Chinese students who spent a semester in Britain and found that, although the majority of students had few psychological or sociocultural adjustment difficulties, they experienced obstacles in social interactions with non-Chinese students. The students' academic performance was negatively correlated with the psychological stress experienced. Ward and Chang (1997) reported that depression, a psychological adjustment, observed by U.S. students studying in Singapore for a semester abroad correlated with different aspects of students' personality, i.e. extraversion. The above studies show the importance of personality dimensions on the sociocultural adaptations of students abroad.

Savicki, Adams, and Binder (2008), using the SCAS, studied a sample of 72 U.S. university students who participated in a three month education abroad program in a major European city and lived in typical homestay arrangements. Students received intercultural communication classes and were engaged in written assignments related to cultural issues. Their results showed that the contact with the dissimilar culture, in the beginning, placed intense demands on students, and later on the stress was decreased. The authors' notion that the "successful reduction of stressors in the early stages set the stage for later freedom and motivation to explore the host culture in more depth" (p. 170) provides a working hypothesis to be examined, related to the length of the education abroad program. In a similar study, Savicki, Cooley, and Donnelly (2007) followed the experiences of 26 students from U.S. universities who participated in an education abroad program in Greece for three months, and they measured several indices of psychological and sociocultural adjustments using several instruments, including SCAS, within the concept of acculturation. The results showed that students relied on their home culture friends to avoid psychological problems. It appears that "in the face of difficulties and with effective on-site support, they [students] met the challenge of acculturative stress and transformed it into a satisfying experience" (p. 189). The authors suggested that future research should consider a larger sample of participants in order for general principles to emerge from such treatment. 


\section{Education Abroad Programs in the Greek Context}

Despite the recent attempt to diversify the global experience for the U.S. students, the majority of the education the students receive abroad still comes from participation in education abroad programs offered by European host institutions. According to the most recent report released by the Institute of International Education (IIE Open Doors, 2011) during the 2009-2010 academic year, $53.5 \%$ of the total 270,604 U.S. students who studied abroad visited the old world. Greece served as a host country for 3,700 students (up 2.3\% from the previous year), which makes it one of the favorite destinations for the U.S. student population visiting European countries. Greece was ranked the seventh most popular destination within the European continent and fifteenth in global preference for students abroad. Athens, Thessaloniki, and five Aegean Islands host the overwhelming majority of the education abroad programs in Greece. Only nine private host institutions of higher learning offer education abroad opportunities, participation in a wide-range of academic courses, have permanent campus facilities, and offer housing accommodations. Other major players in education abroad include American universities and colleges offering their own faculty-led programs, American consortia (most offering a limited spectrum of academic courses), private education foundations, and institutes of fine arts (predominately offering summer short-term experiences in limited art subjects).

Greece can be viewed as an ideal laboratory for the study of cultural aspects of education abroad. The country is a member of the European Union and provides a familiar political and economic environment that resembles most other European countries, yet it is significantly different from the U.S. in several simple and complex cultural aspects. Social differences exist among Greek and American university students, such as the perception of gestures, which play a potential role in comprehension, learning, and judgments about emotional intensities. These differences could widen miscommunication and sometimes could lead to grave, indeed tragic, misunderstanding (Ekman et al, 1987; Gullberg, 2006). Hofstede $(2001,2008)$ proposed significant differences in four major national culture dimensions (Power Distance, Uncertainty Avoidance, Individualism, and Collectivism) in the two countries as they are framed in his model. Taken together, these dissimilarities in Hofstede's cultural dimensions reveal significant differences between the work environments of the two countries. Significant divergence also exists in what the educational systems of these two countries expect as an acceptable set of personal responsibilities from their students. Cultural distance has been recognized as an important factor in adjustment to cultural change and it has been shown to be related to abilities to negotiate new social encounters (Domingues, 1970; Furnham \& Tresize, 1981). Savicki, Adams, Wilde, \& Binder (2008) reminded us, that the number and the intensity of the encounters depend on the cultural distance between the U.S. and the host country. Therefore, the cultural differences observed between the two countries in the work, teaching, and learning environments to which US college students are exposed, could easily produce "culture shock" and would be expected to contribute significantly to students' cross-cultural transitions in Greece. Anecdotal evidence from current education abroad students also supports these claims. 


\section{Purpose of the Study}

There is no evidence in the literature for direct comparison of the sociocultural adaptation brought by the participation of U.S. students in education abroad programs of different lengths. This study will attempt to address this gap by comparing the sociocultural adaptation of education abroad students that results from their participation in both short-term and long-term programs in the same academic institution. Searle and Ward (1990) suggested that the approach of studying sociocultural adaptation by using their SCAS questionnaire should be used in diverse cultural contexts in order to "ascertain the cross-cultural applicability of these findings and to explore further the notion of 'cultural fit"' (p. 460). Greece could serve as a diverse cultural environment for this purpose. This study will be the first research undertaken to report on the sociocultural adaptations of U.S. students participating in education abroad programs in Greece and to directly compare the effects of length of the education abroad on the sociocultural adaptation of U.S. students. In addition, the effects of incorporating intervention activities into the academic and co-curricular activities designed to help students prepare for, gain from, and reflect upon their term abroad as a profound global experience on their sociocultural adaptation is examined. It is hypothesized that a) the sociocultural gains achieved by the students who attend the education abroad program for longterm (three months, academic semester) will be higher than of those achieved by the students who attend the same education abroad program for short-term (four weeks, summer term); b) the sociocultural adaptation of those students who receive intervention will be higher than the students who receive the standard academic and co-curricular education abroad program.

\section{Method}

\section{Participants and Program Description}

Three groups of students participating in the summer session and fall semester education abroad program offered by a private liberal arts college were used in this study. Located in Thessaloniki (Northern Greece), a metropolitan city of more than one million inhabitants, the college maintains a well-established education abroad program and serves as a host institution of more than 250 undergraduate U.S. students per year. The first group (termed short-term, S-Term), participated in a four week academic program (28 students, 27.7/72.3 male to female ratio, overall mean age $20.8 \pm$ 1.46 years). The second group (termed long-term, L- Term), participated in a three month academic semester (44 students, 28.4/71.6 male to female ratio, overall mean age $20.3 \pm 1.9$ years). The third group (termed long-term intervention, L-Term-Inter), participated in a three month academic semester and received additional formal instruction about living and learning abroad (57 students, 43/56.7 male to female ratio, overall mean age $19.1 \pm 0.7$ years). The overwhelming majority of the first and second groups of students were from home institutions located in different Eastern and Midwestern states, whereas the third group was composed entirely of students from a major university located in Massachusetts. All students, regardless of their groups, in addition to their academic schedule, participated in the same co-curricular activities designed to enrich their cultural experience while in Greece. All three U.S student groups were enrolled in classes taught in English. Greek, non-Greek, and other fellow U.S. students were part of the mixture of the classes. During the 
day, the students had the opportunity to interact while on campus in a multinational environment and were allowed to live in housing in the center of the city. The college's education abroad program uses non-homestay arrangements for its students (independent one-bedroom or two-bedroom apartments in a dormitory-like building). This arrangement encourages students to have independent cultural encounters with the locals from the very first day of their arrival in the city. The L-Term-Inter group received, in addition to the standard academic and co-curricular activities the other two groups were exposed to, formal instruction about living and learning abroad. The students of this group were obliged to register in a Global Experience class designed to help students prepare for, gain from, and reflect upon their term abroad as a profound global experience. The course was designed in such a way to include, in addition to the course readings, a variety of activities such as workshops, seminars, discussions, and local civic engagement. It was intended to challenge students to become global citizens and ambassadors by actively participating in their own learning community, as well the greater study abroad community and beyond. All students in the LTerm-Inter group were engaged in service learning activities, posting weekly blogs which included their observations and reflections on local cultural issues, and creating digital storytelling spots related to their cultural experience. The students in this group received three semester credits for their mandatory participation in this course. They were also assigned an apartment director who was responsible for the needs of the students on a 24-hour basis. All students from the three groups were asked for their voluntary participation in this research at the end of the completion of their academic program.

\section{Instrument and Statistical Analysis}

SCAS has proven psychometric properties, provides a "culture learning paradigm", and "can be easily modified according to the characteristics of the sojourning sample" (Ward \& Kennedy, 1999, p.662). The 29 item questionnaire (in our study 28 questions were presented to the subjects since none of the participants lived in home stay arrangements), includes two subscales based on factor analysis: the Impersonal Endeavors-Perils (ImpEn-P) subscale is composed of seven items, presents $8.7 \%$ of variance, and relates to management of impersonal interactions and/or awkward situations. The Cultural Empathy-Relatedness (CultEm-R) subscale is composed of 13 items, presents 32.1\% variance, and relates to understanding of local perspectives, values, world views, and communication. The Likert scale presented for each question scores the responses of the students ranging from $1=$ no difficulty to 5 = extreme difficulty. Strong aspects of the instrument include the following: it is based on the theory of acculturation; it tracks key intercultural adaptation issues; it gives several scores to interpret; and it predicts overall progression and adaptation (Savicki, 2009; Ward, 2001). The instrument is reporting a strong internal consistency (.75 to .91$)$, reliability (.89 to .92 alpha coefficients), strong criterion validity, and has been suggested as a valuable tool for program evaluation (Paige \& Stallman, 2008; Ward \& Kennedy, 1999). The study was approved by the Institutional Review Board and the questionnaire was administered by an experienced faculty member at the end of the students' academic program. Student participation was voluntary and responses were kept anonymous. Data were analyzed for statistical difference using the T-test. 


\section{Results}

The top five fields of study for all the participants in this research were from social sciences (27\%), business and management (24\%), humanities (15\%), fine or applied arts (9\%), and physical and/or life sciences (4\%). This mixture of students could be considered a typical group of students attending education abroad programs (IIE Open Doors, 2011). Figure 1 graphically depicts the means and standard deviations for the three SCAS scores for the three groups examined.

Figure 1. SAS Score S-Term=Summer Term, L-Term=Long Term, L-Term Inter=Long Term Intervention, ImpEn-P=Impersonal Endeavors-Perils, CultEm-R=Cultural Empathy-Relatedness

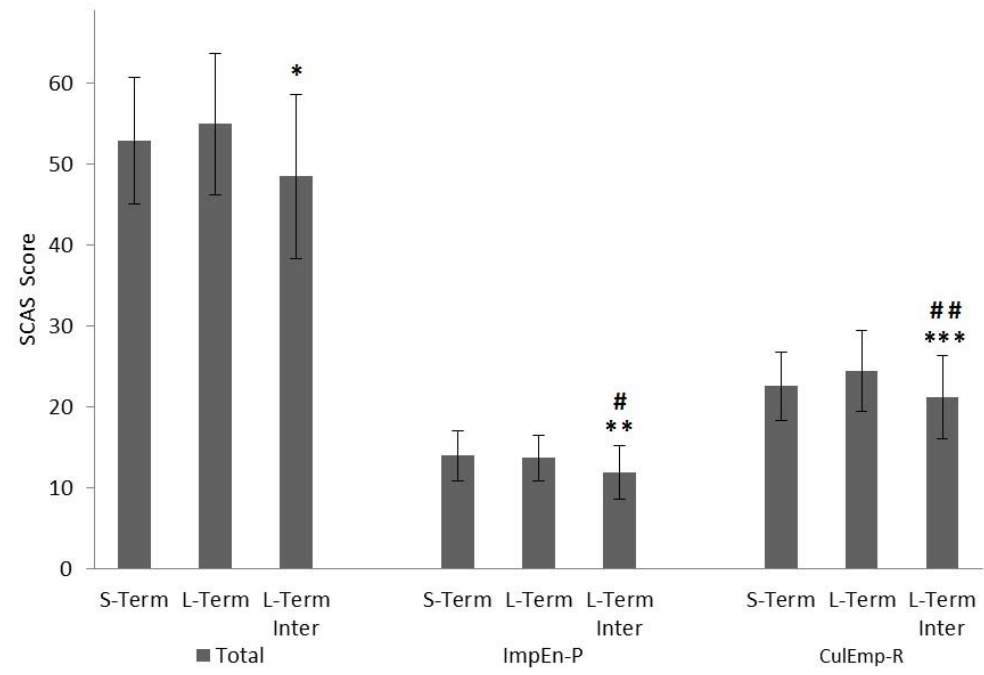

Note: Significant differences between L-Term and L-Term Inter groups at $\mathrm{p}<.001 *, .007 * *$, or .002 $* * *$. Significant difference between S-Term and L-Term Inter at $\mathrm{p}<.03$ \# or $.008^{\# \#}$. Lower scores indicate smaller difficulty in social interactions

Table 1 shows the differences in the mean scores obtained in the three SCAS scores (Total, ImpEn-P, and CultEm-R) for the three groups (S-Term, L-Term, and L-Term Interv) examined. There were no statistical significant differences between the S-Term and the L-Term in the total score, and the two subscales obtained from the SCAS questionnaire. Comparison between the LTerm and the L-Term-Inter groups however, revealed significant differences between the two groups for all the three scores of the SCAS measured. In addition, statistically significant differences were recorded for the two subscales of the instrument between the S-Term and L-Term-Inter. 
Table 1 Mean scores and standard deviations $( \pm S D)$ of the sociocultural adjustment for the total score and the two subscales for the three groups examined. Abbreviations and significant differences as noted in Fig. 1

\begin{tabular}{ccccc} 
& & Total & ImpEn-P & CultEm-R \\
& & & & \\
\hline Group & $\mathbf{n}$ & Mean \pm SD & Mean \pm SD & Mean \pm SD \\
& & & & \\
\hline S-Term & 28 & $52.96 \pm 7.97$ & $14.00 \pm 3.12$ & $22.61 \pm 4.33$ \\
& & & & \\
\hline L-Term & 44 & $54.98 \pm 8.83$ & $13.73 \pm 2.89$ & $24.54 \pm 5.07$ \\
\hline L-Term Inter & 57 & $48.51 \pm 10.23^{*}$ & $11.96 \pm 3.39 * *^{\#}$ & $21.25 \pm 5.19 * * * \#$
\end{tabular}

Note: Significant differences between L-Term and L-Term Inter groups at $\mathrm{p}<.001 *, .007 * *$, or $.002 * * *$. Significant difference between S-Term and L-Term Inter at $p<.03{ }^{\#}$ or $.008^{\# \#}$. Lower scores indicate smaller difficulty in social interactions.

\section{Discussion}

Global education is becoming a mainstream term in higher education as more students are flocking to other countries to experience cultural and academic programs abroad. American institutions are advocating for greater student mobility across borders. Universities, colleges, and community colleges recognizing student globalization as a campus priority are expanding or are developing new programs offering education abroad opportunities for their students despite current adverse economic conditions (American College of Education, 2010; IES Abroad, 2010; IIE Open Doors, 2011). Assessing education abroad programs takes new challenges as pressures mount to satisfy accreditors and granting agencies for communication of student learning outcomes. EAPS practices, both at home and host institutions will be scrutinized in the future at many levels about the effectiveness of their programs (American College of Education, 2006). In the light of these developments, and taking into consideration the pressures of accountability in higher education for improved performance and demonstration of the effectiveness of programs, this research takes on increased importance.

There is ample evidence in the literature which shows increased student gains in overall crosscultural development and understanding. Intercultural development, intercultural sensitivity, global understanding, global awareness, attitudes, knowledge, competence, intelligence, and intercultural communication skills are some terms and constructs used to report these gains which come as a result of participation in short-term education abroad programs. The short term education abroad program (programs range from week long to less than eight weeks long) is increasing in popularity (Donnelly-Smith, 2009) and administrators who are proponents of them need to defend the benefits emerging from such programs. This research is among the few to report on the level of sociocultural adaptation of U.S. students who attended education abroad programs of short duration. It is also the first to make a direct comparison of the status of the sociocultural adaptation between the short term and the long term education abroad programs. 
The results provide evidence of high achievement of sociocultural adaptation scores for all students regardless of the time spent in the new culture. As Table 1 shows, there was no difference between the S-Term and L-Term education abroad programs in sociocultural adaptation in all three measurements recorded (total score and two subscales). Students found it relatively easy to adapt to the new culture regardless of the time spent abroad. Even students who stayed for a short time (period of four weeks), scored very low on the SCAS (lower scores indicate less difficulty in social interactions). Although the students in this study recorded their perceived sociocultural adaptation, the low scores obtained in either short-term or long-term (mean scores of two or less in the five point Likert scale in all three SCAS measurements recorded in this study), show that their sociocultural adaptation might last less time than what was previously thought. Savicki, Adams, Wilde, \& Binder (2008), citing the work of others, proposed that the "sociocultural adjustment is most difficult in the earliest stages of transition, but within 4 to 6 months it reaches a plateau" (p. 113). Since the students in all three groups studied in our investigation scored high on the sociocultural adaptation (low SCAS scores), even after four weeks of staying abroad, their proposal needed to be re-examined. Leong \& Ward (2000) suggested that this process reaches a plateau in about four to six months, and eventually the sojourner will be able to "deal with the demands of the new environment" (Leong \& Ward, 2000, p. 767). The results of this study suggest that rapid gains in sociocultural adaptation take place in well-designed education abroad environments as the one described in this study, and the course of sociocultural adaptation might unfold much faster than it was previously suggested. The results may have repercussions on the work of others too, who suggested that the optimum range of time for intercultural gains to take place is 13-18 weeks (Vande Berg, 2008).

The results of the present study are in agreement with those obtained by Allen, Dristas, and Mills (2006) who used the SCAS as a measure for the cultural learning for a group of homestay and non-homestay study abroad junior high school students. The authors found that spending a summer session for four to five weeks in France, Italy, and Spain as a benefit of foreign language learning does have an effect on sociocultural adaptation. The authors also noted that there were significant differences between homestay and non-homestay students in the way they experienced difficulties in finding cultural practices and cultural products (shopping, finding their way around, and using to transport system, finding food), with homestay students encountering more difficulties.

Pedersen $(2010,2011)$ reported that the outcomes of education abroad programs are questioned regarding the intercultural effectiveness of students if they are not accompanied by intentional pedagogy. Her conclusions reiterate the need for well-structured education abroad programs and mentoring that will provide intentional supplementation to the overall cultural education abroad experience (Goldstein \& Kim, 2006; Talburt \& Stewart, 1998; Vande Berg, 2007; Vande Berg, 2008; Vande Berg, 2009). In the present study, the Global Experience class in which the LongTerm-Inter students were registered appeared to result in significantly higher sociocultural adaptation scores compared to the Long-Term group of students who were receiving the same academic coursework but no further cultural intervention during the semester. The course outcomes and the activities were designed in such a way that students would have the opportunity to develop an enhanced appreciation of the host country culture, language, history and cultural events; practice being a critical observer and reflect on the experience(s); engage in service learning experiences within the larger metropolitan community; and cultivate an increased understanding of one's own 
culture. It appears that these course outcomes significantly altered the students' ability to adapt to the new culture in their host country.

From the results of the present study, it appears that the students who received intervention scored lower on the SCAS (had less difficulty in social interactions) for both subscales. The ImpEn-P subscale of sociocultural adaptation relates to the management of interpersonal interactions when dealing with people of authority, governmental structures and hierarchies, bureaucracy and, in general, with unpleasant behaviors. According to Harris, Moran, and Moran (2004), Greece and U.S. scores in two national culture dimensions (Power Distance and Uncertainty Avoidance) are diametrically opposite, and reflects the view that the "work, teaching, and learning environments of the two countries are positioned on the antipode" (p. 18). In this view, it is expected that social and cultural structures need to be enhanced in Greece and provide the framework for increased difficulties for sociocultural adaptation of the students. The ImpEn-P subscale of sociocultural adaptation addresses issues which relate to adapting to difficult situations involving conformity. For a U.S. student participating in an education abroad program in Greece, conformity means dealing with the perceived or actual pressure exerted on her by the host society and culture. On the other hand, the CultEm-R subscale of sociocultural adaptation relates to cognition when dealing with communicating and understanding, regarding the host country's religion, food, folklore activities, or relationships of the opposite sex. This subscale of the instrument addresses issues that put relatively less pressure on the students to conform and allows them to explore more easily their abilities to "fit in" culturally.

This research emphasizes the significance of the incorporation of intentional outcomes on students' sociocultural adaptation and they are supported by previous empirical research on facilitation of cultural gains while abroad. Savicki (2008) stressed the importance of appropriate preparation of students before the initiation of any education abroad program. Similarly, Bateman (2002) reported that students could increase their understanding, positive attitudes, and tolerance by using specific classroom activities and student reports aimed at cultural issues of the host country. Conducting ethnographic interviews could be used as one way to promote openness toward culture learning. Savicki, Cooley, and Donnelly (2007), while studying the acculturative stress, appraisal, coping, and intercultural adjustment of a small sample of students who spent a three month academic semester in Greece, underlined the significance of the intense focus on the host culture parallel to students' engagement with their academic work. The authors stated that "it appears that in the ability to stay engaged, to focus on the problematic situation rather to ignore them, and the ability to find the "silver lining" were related to socio-cultural adjustment" (p. 188). Recently Pedersen $(2009,2010)$ has stressed the importance of incorporating intentional pedagogy focused on outcomes of intercultural effectiveness. Using short term (two weeks) and long term (year-long) education abroad "island" classroom research, during which students received or did not receive intentional intervention, Pedersen showed that incorporating pedagogy into the cultural experience could make a difference in students' intercultural growth. Alternative models of engaging students using appropriately designed constructivist approaches, which expose students in well-designed, short-term education abroad programs (Orpet-Long, Akande, Purdy, \& Nakano, 2010), are worth examining further and they certainly strengthen the assumptions made. 
The strong components of this study include the relatively large sample of education abroad students used to study their sociocultural adaptation. In previous reports appropriate sample size was considered a limitation (Savicki, Cooley, \& Donnelly, 2007). This is the first study to implicate the importance of intentional pedagogy in the sociocultural adaptation of students studying abroad. The absence of measurements of other parameters, which could influence the outcome of the present results, contributes to the limitations of this study (previous cultural knowledge and traveling, language fluency, and cultural distance). This implies that future studies should take into consideration the measurement of specific personality dimensions, along with sociocultural adjustments using appropriate instruments. When Lee $\&$ Bradley (n.d.) assessed the acculturative stress among international students studied in the U.S., they concluded that students with higher levels of self-efficacy experience the lowest level of acculturative stress. Although the results of their study are not directly transferable to U.S. students studying abroad, they do emphasize the importance of the consideration of personality dimensions on similar to sociocultural adaptation constructs. The incorporation into the research design of other instruments which measure similar to sociocultural adaptation constructs, as it has been suggested in the past (Savicki, Cooley, \& Donnelly, 2007; Savicki, Downing-Burnette, Heller, Binder, \& Suntinger, 2004), could be taken into consideration when planning to study the effects of incorporating intervention culture-related activities into the education abroad programs.

\section{Conclusions}

Overall, the results of the present study suggest that both short term and long term education abroad programs result in comparable sociocultural adaptations for the students. In order for the students to be culturally adjusted and adapted to a new culture, well-designed intentional interventions should be incorporated to the students' academic programs and co-curricular activities. It appears that some study abroad participants are "admirably self-sufficient" whereas others "simply do not know how to go about learning in a new and different cultural environment" (Vande Berg, 2007, p. 394). Facilitating this understanding in the new cultural environment by incorporating interventions appears to result in significant increases in sociocultural adaptation as this study shows. Simply sending students in education abroad programs will not facilitate global competence and citizenship. Only well-developed and implemented education abroad destinations, which are designed to deliver specific cultural outcomes, will survive the scrutiny imposed by the increased accountability on education abroad programs. Colleges and universities abroad could serve as ideal platforms for developing the skills and abilities of "intercultural maturity" (King and Baxter Magolda, 2005) and practitioners in EAPS units need to be careful in designing and implementing short-term or long-term education abroad programs for their students. More research on the sociocultural adaptation of U.S. students taking into consideration the incorporation of other relevant to sociocultural adaptation constructs will result in a fully developed picture of the contribution of the education abroad experiences to the global cultural awareness.

\section{References}

Allen, H.W., Dristas, V., \& Mills, N. (2006). Cultural learning outcomes and summer study 
abroad. In M. Mantero, (Ed.), Identity and second language learning: Culture, inquiry, and dialogic activity in educational contexts (pp. 187-214). Charlotte, NC: Information Age Pub. American College of Education (2006). Articulating learning outcomes. American Council of Education. International Education. Retrieved January 8, 2012 from http://www.acenet.edu/AM/Template.cfm?Section=Intl\&Template=/CM/HTMLDisplay.cfm \&ContentID $=19462$.

American College of Education (2010). Study abroad enrollments remain steady. Presidency, 13(1), 10.

Bateman, B. A. (2002). Promoting openness toward culture learning: Ethnographic interviews for students of Spanish. The Modern Language Journal, 80, 318-331.

Donnelly-Smith, L. (2009). Global learning through short-term study abroad. Peer Review, 11(4), 12-15.

Ekman, P., Friesen, W., O'Sullivan, M., Chan, A., Diacoyanni-Tarlatzis, I., Heider, K., et al. (1987). Universals and cultural differences in the judgments of facial expressions of emotion. Journal of Personality and Social Psychology, 53(4), 712-717.

Goldstein, S.B. \& Kim, R. I. (2006). Predictors of US college students' participation in study abroad programs: A longitudinal study. International Journal of Intercultural Relations, $\quad 30,507-$ 521.

Gullberg, M. (2006). Some reasons for studying gesture and second language acquisition (Hommage à Adam Kendon). International Review of Applied Linguistics in Language Teaching, 44(2), 103124.

Furnham, A., \& Tresize, L. (1981) The mental health of foreign students. Social Science and Medicine, 17, 365-370.

Hofstede, G. (2001). Culture's consequences: comparing values, behaviors, institutions, and organizations across nations (2nd ed.). Thousand Oaks, CA: Sage.

Hofstede, G. (2008, May 8). Cultural Differences in Teaching and Learning. Paper presented at the FUHU Conference on Education and Training in the Multicultural Classroom. Copenhagen, Denmark. Retrieved March 10, 2012 from http://fuhu.dk/filer/FBE/Arrangementer/Denmark\%20Unlimited\%20080508/FBE geert hofs tede_teaching_learning.pdf

IIE Open Doors (2011). Open Doors fast facts. Retrieved on June 7, 2012 from http://www.iie.org/en/Research-and-Publications/Open-Doors

IIE Abroad (2010). Membership survey report. 2009-2010 results. Retrieved June 2, 2012 from http://ww1.prweb.com/prfiles/2010/09/01/3902264/2010IESAbroadMembershipSurvey.pdf

King, P. M., \& Baxter Magolda, M. B. (2005). A developmental model of intercultural maturity. Journal of College Student Development, 46(6), 571-592.

Lee, S. \& Bradley,K.D. (n.d.). Relation between general efficacy, assertiveness, spirituality, and acculturative stress among international students. Retrieved June 1, 2012 from http://www.uky.edu/ - kdbrad2/InternationalStudents.pdf

Leong, C. \& Ward, C. (2000). Identity conflict in sojourners. International Journal of Intercultural Relations, 24, 763-776.

Orpet-Long, S., Akande, Y.S., Purdy, R.W., \& Nakano, K. (2010). Deepening learning and 
inspiring rigor: bridging academic and experiential learning using a host country approach to a study tour. Journal of Studies in International Education. 14: 89-111.

Paige, R.M. \& Stallman, E.M. (2008). Using instruments in education abroad outcomes assessment. In M.C. Bolen (Ed.), A guide to outcomes assessment in education abroad (pp. 137-161). Forum on Education Abroad: Carlisle,PA.

Pedersen, P. (2009). Teaching towards an ethnorelative worldview through psychology study abroad. Intercultural Education, 20, 73-86. Retrieved June 10, 2012 from http://www.idrinstitute.org/allegati/IDRI t Pubblicazioni/20/FILE Documento.pdf

Pedersen, P. (2010). Assessing intercultural effectiveness outcomes in a year-long study abroad program. International Journal of Intercultural Relations, 34(1), 70-80.

Pedersen, P. (2011). Infusing intercultural into your international. Examples, outcomes, and participant dialogue [Video file]. Retrieved March 21, 2012 from

http://mediamill.cla.umn.edu/mediamill/display/110485

Savicki, V. (2008).Developing intercultural competence and transformation; Theory, research, and applications in international education. Sterling, VA: Stylus.

Savicki, V. (2009, May). Socio-cultural adaptation scale. In D. Deardorff Assessment toolbox for international educators. Symposium presented at the NAFSA Annual Conference, Los Angeles, CA. Retrieved April 20, 2012 from http://www.saintmarys.edu/ -cwil/php/intercultural.learning/IILOutcomes.php

Savicki, V., Adams, I., Wilde, A. \& Binder, F. (2008). Intercultural Development: Topics and Sequences. In V. Savicki, (Ed.), Developing intercultural competence and transformation. Theory, research, and application in international education (pp. 154- 172). Sterling, VA: Stylus Pub.

Savicki, V., Cooley, E. \& Donnelly, R. (2007). Acculturative stress, appraisal, coping, and intercultural adjustment. In V. Savicki, (Ed.), Developing intercultural competence and transformation. Theory, research, and application in international education (pp. 173-192). Sterling, VA: Stylus Pub.

Savicki, V., Downing-Burnette, R., Heller, L., Binder, F., \& Suntinger, W. (2004). Contrasts, changes, and correlates in actual and potential intercultural adjustment. International Journal of Intercultural Relations, 28, 311-329.

Searle, W. \& Ward, C. (1990). Prediction of psychological and sociocultural adjustment during cross-cultural transitions. International Journal of Intercultural Relations, 14, 449-464.

Searle, W. \& Ward, C. (1999). The prediction of psychological and sociocultural adjustment during cross-cultural transitions. International Journal of International Relations, 14, 449-464.

Spencer-Oatey, H. \& Xiong, Z. (2006). Chinese student's psychological and sociocultural adjustments to Britain: An empirical study. Language Culture and Curriculum, 19(1), 37-53.

Talburt, S. \& Stewart, M.A. (1999). What's the subject of study abroad?: Race, gender, and "living culture". The Modern Language Journal, 83(2), 163-175

Vande Berg, M. (2007). Intervening in the learning of U.S. students abroad. Journal of Studies in International Education, 11, 392-399.

Vande Berg, M. (2008, October 13). Intervening in students learning abroad: A research based inquiry. Paper presented at the International Education Conference, Moving Beyond Mobility, Berlin, Germany. Retrieved February 10, 2012 from http://www.movingbeyondmobility.org/ 
Vande Berg, M. (2009). Intervening in the learning of U.S. study abroad. Journal of Studies in International Education. 11(3-4), 392-399.

Ward, C. (2001). The A, B, Cs of acculturation. In D. Matsumoto (Ed.), The handbook of culture and psychology (pp. 411-445). Oxford: Oxford University Press.

Ward, C. \& Chang, W.C. (1997). "Cultural fit": A new perspective on personality and sojourner adjustment. International Journal of Intercultural Relations, 21(4), 525-533.

Ward, C. \& Kennedy, A. (1993). Where's the "culture" in cross-cultural transition? Comparative studies of sojourner adjustment. Journal of Cross-cultural Psychology, 24, 221-249.

Ward, C. \& Kennedy, A. (1994). Acculturation strategies, psychological adjustments, and sociocultural competence during cross-cultural transition. International Journal of Intercultural Relations, 18, 329-343.

Ward, C. \& Kennedy, A. (1999). The measurement of sociocultural adaptation. International Journal of Intercultural Relations, 22, 659-677.

Ward, C. \& Searle, W. (1991) 'The impact of value discrepancies and cultural identity on psychological and sociocultural adjustment of sojourners', International Journal of Intercultural Relations, 15(2), 209-224.

\section{Author Note}

This study was conducted as part of the requirements for the completion of the Master of Science Degree in the Student Affairs in Higher Education Program of the Department of Educational Leadership, Bayh College of Education, Indiana State University. The author would like to thank Dr. Victor Savicki, who reviewed an earlier version of this article, and other anonymous reviewers. 